\title{
ESTUDO DAS PROPRIEDADES DE ESCOAMENTO DE MATERIAIS GRANULARES DA CONSTRUÇÃO CIVIL
}

\author{
D. B. BAIÃO, R. CONDOTTA* \\ Centro Universitário da FEI, Departamento de Engenharia Química \\ *e-mail: rcondotta@fei.edu.br
}

\begin{abstract}
RESUMO
Estudou-se o comportamento de misturas formuladas a partir de quartzos de denominação \#200, \#600 e areia fina, variando-se a fração mássica dos quartzos. As misturas geradas foram submetidas a testes para determinação da fluidez de pós e caracterização dos materiais quanto as suas propriedades físicas essenciais. Conforme o proposto pela teoria, as amostras constituídas por partículas menores apresentaram valores inferiores para densidade aparente e compactada, porosidade de compressão, energia básica de fluxo, índice de fluxo e relação de aeração; e valores superiores para a densidade de compressão, porosidade aparente, porosidade compactada, compressibilidade, índice de Hausner, ângulo de repouso e energia de aeração. Os resultados obtidos evidenciam a coesividade dessas amostras, uma vez que a operação de compactação intervém nas propriedades dos materiais não coesivos com mais intensidade enquanto que as propriedades dos materiais coesivos sofrem maior interferência pelas operações que envolvem compressão. Os testes dinâmicos, por sua vez, demonstraram que as amostras mais coesivas apresentam maior resistência ao escoamento em condições de aeração do que em condições sem consolidação. Em se tratando de materiais de natureza química semelhante, o efeito da coesão foi o principal agente modificador da fluidez das misturas estudadas, sendo influenciado proporcionalmente pela fração mássica de finos.
\end{abstract}

\section{INTRODUÇÃO}

Nas condições normais de atmosfera, muitas substâncias apresentam estabilidade no estado sólido o que lhes confere algumas vantagens quanto ao manuseio, transporte e armazenamento, forma e volume definidos, dentre outras.

No entanto, em se tratando de materiais particulados, esses fatores podem se tornar inconvenientes em processos nos quais não há um estudo que auxilia nas operações industriais e no projeto de equipamentos que empregam estes tipos de materiais.
Apesar da diversidade e da vasta utilização de sólidos particulados em escala industrial, o estudo do comportamento e escoamento de materiais pulverulentos ainda é pouco explorado, talvez pelo fato de que pós são geralmente matérias primas de baixo custo e com baixo valor agregado (CAMPOS, 2012). Ou pelo fato de que, diferentemente dos líquidos, que possuem sua fluidez classificada segundo sua viscosidade, não existe uma definição concreta nem uma unidade específica para se descrever o fluxo dinâmico de materiais pulverulentos (FREEMAN, 2006). 
O negligenciamento da tecnologia de partículas pode resultar em perda de produção, má qualidade do produto, risco para a saúde ou explosão; a compreensão básica da maneira em que os pós se comportam pode minimizar estes problemas, resultando em menos tempo de inatividade do processo, melhorias no controle de qualidade e emissões ambientais (RHODES, 2008).

Desta forma, este trabalho utilizou areia e quartzo, materiais comumente utilizados no segmento da construção civil, objetivando identificar as variáveis que podem influenciar no escoamento de misturas destes materiais, determinando a granulometria, as densidades real e aparente, a porosidade e o ângulo de repouso.

Entretanto, estas são análises que classificam os pós em condições estáticas ou na iminência do movimento; com a finalidade de prever o comportamento dos materiais pulverulentos em condições dinâmicas, o uso de reômetros de pós é indispensável para simulação e análise do movimento desses materiais (FREEMAN, 2006). Por este motivo, ensaios empregando um reômetro de pó FT-4 também foram realizados neste trabalho.

\section{METODOLOGIA}

No intuito de se estudar os principais elementos que afetam a fluidez e interferem nas propriedades dos materiais pulverulentos, inicialmente aferiu-se o comportamento das substâncias comerciais de areia e quartzo. Posteriormente, avaliou-se os possíveis efeitos das diferentes granulometrias e frações mássicas em misturas confeccionadas a partir destas amostras comerciais.

Para tanto, foram realizados ensaios experimentais para a caracterização das amostras quanto as suas propriedades físicas essenciais, tais como granulometria, densidade real e aparente, compressibilidade e porosidade, propriedades estas que influenciam diretamente na fluidez de materiais na forma de pós.

Além destes testes convencionais em condições estáticas, análises destes materiais em condição dinâmica também foram realizadas em testes reológicos com e sem aeração.

\subsection{Materiais}

Três diferentes materiais comerciais foram empregados: Areia de construção dita fina, e Quartzo com especificação \#200 (mesh 200) e \#600 (mesh 600). Diferentes teores das amostras de quarzto foram adicionados de areia fina originando misturas com teores de $3,6,10,15,20,30 \%$ de quartzo, resultando num total de 15 amostras (12 misturas e 3 amostras monodispersas). Todas as amostras foram secas em estufa a $70^{\circ} \mathrm{C}$ por 12 horas.

\subsection{Caracterização das Amostras}

A análise granulométrica das partículas foi realizada no equipamento BlueWave, da marca MicroTrac, e o resultado expresso em porcentagem volumétrica. $\mathrm{O}$ método utilizado foi o de via úmida, sendo a água o meio dispersante.

Para a determinação da densidade real das partículas sólidas, foi utilizado o aparelho Gas Pycnometer, modelo AccuPyc II 1340, da marca Micromeritics, dotado de uma câmara de amostragem de $10 \mathrm{~cm}^{3}$, empregando gás hélio. $O$ sistema contendo a amostra a ser analisada passou por um total de 100 purgas seguido de 10 análises para a determinação da densidade real, sendo o resultado final um valor médio destas 10 medidas.

A determinação das densidades aparente e compactada das amostras foi realizada em uma proveta de $200 \mathrm{ml}$ e mediante a relação massa e volume. Em seguida, esta mesma amostra foi submetida ao equipamento AutoTap, marca Logan, que ocasiona a compactação do material (redução do volume ocupado pela amostra) através de choques sucessivos. A densidade compactada foi 
estimada após 50, 100, 150, 200, 250, 1000, 1500 e 2000 batidas, segundo a metodologia II da U.S. Pharmacopeia (USP, 2006).

As porosidades das amostras não compactada (bulk) e compactada foram então obtidas através de relações específicas entre as densidades real da partícula, de bulk e do estado compactado.

O ângulo de repouso foi estimado pela inclinação da superfície livre de uma pilha formada com o material pulverulento sobre uma superfície plana. Este teste foi realizado em duplicata com o auxílio de um dispositivo alternativo constituído de um funil analítico de vidro fixado em um suporte universal e situados a $23,7 \mathrm{~cm}$ acima de uma placa de Petri invertida de 9,2cm de diâmetro. Com a finalidade de minimizar a formação de aglomerados das partículas, foi utilizado uma peneira de $1 \mathrm{~mm}$ de apertura acima do funil.

\subsection{Reômetro de Pó FT4}

O aparelho FT-4 (Freeman Technology) é um reômetro de pó cuja principal função e diferencial é a sua capacidade em medir a força axial e rotacional (torque) de uma lâmina torcida de $48 \mathrm{~mm}$ de comprimento (geometria especifica e patenteada para esta aplicação) ao se mover através de um leito de material pulverulento compreendida num recipiente de $160 \mathrm{ml}$. A energia necessária para deslocar o pó para permitir a passagem da lâmina fornece parâmetros da fluidez do pó no estado dinâmico.

Outro diferencial do equipamento é a rotação da lâmina torcida, quando submetida à rotação no sentido anti-horário causa $o$ movimento do material e, quando submetida à rotação horária, homogeneíza a amostra aliviando as tensões causadas durante os ensaios (SANTOS, CONDOTTA, 2014).

Inicialmente, todas as amostras foram submetidas ao teste de estabilidade e de fluxo variável, segundo metodologia "standard" descrita no manual do equipamento (FREEMAN, 2008).
O teste de estabilidade é realizado com uma velocidade fixa de $100 \mathrm{~mm} / \mathrm{s}$ no sentido anti-horário e tem como finalidade verificar se a amostra apresenta um comportamento facilmente reprodutível, não sofrendo qualquer alteração quando imposta ao movimento (abrasão, segregação, quebra). Esta etapa é realizada 7 vezes e, sendo o comportamento aceitável, inicia-se o teste do fluxo variável com quatro velocidades reduzidas diferentes da lâmina $(100,70,40$ e $10 \mathrm{~mm} / \mathrm{s}$ ), verificando a variação da energia necessária para movimentar a amostra sob estas novas velocidades. Ao término destes dois testes, o aparelho forneceu a energia básica de fluxo (BFE) expressa em mJ, que é a energia dispendida para deslocar a lâmina torcida através da amostra de pó no $7^{\circ}$ ensaio (após estabilidade atingida), e o índice de fluxo (FRI), que é uma relação entre as energias dispendidas no último ensaio de menor velocidade rotação $(10 \mathrm{~mm} / \mathrm{s})$ e a maior velocidade $(100 \mathrm{~mm} / \mathrm{s})$.

$\mathrm{O}$ teste de compressibilidade consiste em comprimir diretamente $85 \mathrm{ml}$ de amostra com auxílio de um pistão e analisar a redução do volume inicial em função da força normal aplicada. Foram realizadas compressão direta das amostras com $0,5,1,2,4,6,8,12$ e 15 $\mathrm{kPa}$ e a compressibilidade expressa em porcentagem de redução em relação ao volume inicial.

O teste de aeração realizado foi análogo ao teste de estabilidade, onde estima-se a energia dispendida pela lâmina ao atravessar o leito de pó, mas desta vez, com a injeção ar na base do recipiente de $260 \mathrm{ml}$, cuja velocidade do ar varia de $0 \mathrm{~mm} / \mathrm{s}$ a $40 \mathrm{~mm} / \mathrm{s}$.

\section{RESULTADOS}

Os resultados das diversas análises realizadas estão apresentados na Tabela 1 .

As curvas de distribuição granulométrica para misturas de areia e quartzo \#600 e areia e quartzo \#200 estão apresentados nas Figuras 1 e 2, respectivamente. 
Tabela 1 - Resultados das análises de caracterização das amostras comerciais e misturas.

\begin{tabular}{|c|c|c|c|c|c|c|c|c|c|}
\hline \multirow{2}{*}{ Parâmetro Analisado } & \multirow{2}{*}{ Amostra } & \multirow{2}{*}{$\begin{array}{c}\text { Areia } \\
0 \% \\
\end{array}$} & \multicolumn{6}{|c|}{ Teor de Quartzo na amostra de Areia } & \multirow{2}{*}{$\begin{array}{c}\text { Quartzo } \\
100 \% \\
\end{array}$} \\
\hline & & & $3 \%$ & $6 \%$ & $10 \%$ & $15 \%$ & $20 \%$ & $30 \%$ & \\
\hline Diâmetro Médio Vol. & Quartzo \#600 & 270,80 & 270,20 & 262,00 & 236,50 & 226,50 & 209,20 & 148,60 & 9,55 \\
\hline $\mathrm{dv}_{(4,3)}(\mu \mathrm{m})$ & Quartzo \#200 & 270,80 & 261,60 & 253,20 & 234,70 & 226,30 & 210,40 & 190,90 & 23,88 \\
\hline Diâmetro Médio & Quartzo \#600 & 263,40 & 260,00 & 256,10 & 238,30 & 243,70 & 226,90 & 150,40 & 8,35 \\
\hline $\mathrm{d}_{50 \%}(\mu \mathrm{m})$ & Quartzo \#200 & 263,40 & 251,60 & 249,40 & 235,50 & 233,80 & 224,60 & 206,90 & 19,75 \\
\hline Densidade Partícula & Quartzo \#600 & 2,64 & 2,66 & 2,64 & 2,64 & 2,65 & 2,63 & 2,64 & 2,63 \\
\hline$\rho_{\text {part }}(\mu \mathrm{m})$ & Quartzo \#200 & 2,64 & 2,65 & 2,64 & 2,64 & 2,66 & 2,65 & 2,65 & 2,61 \\
\hline Densidade Aparente & Quartzo \#600 & 1,45 & 1,43 & 1,43 & 1,42 & 1,37 & 1,33 & 1,20 & 0,70 \\
\hline$\rho_{\text {bulk }}\left(\mathrm{g} / \mathrm{cm}^{3}\right)$ & Quartzo \#200 & 1,45 & 1,44 & 1,45 & 1,44 & 1,44 & 1,39 & 1,40 & 0,90 \\
\hline Densidade Comp. 2000 batidas & Quartzo \#600 & 1,54 & 1,58 & 1,64 & 1,70 & 1,78 & 1,83 & 1,89 & 1,38 \\
\hline$\rho_{\text {tapped }}\left(\mathrm{g} / \mathrm{cm}^{3}\right)$ & Quartzo \#200 & 1,54 & 1,54 & 1,64 & 1,70 & 1,73 & 1,80 & 1,88 & 1,68 \\
\hline Porosidade Aparente & Quartzo \#600 & 0,45 & 0,46 & 0,46 & 0,46 & 0,48 & 0,49 & 0,55 & 0,73 \\
\hline$($ bulk porosity $)-\varepsilon$ & Quartzo \#200 & 0,45 & 0,46 & 0,45 & 0,46 & 0,46 & 0,48 & 0,47 & 0,66 \\
\hline Porosidade Comp. 2000 batidas & Quartzo \#600 & 0,42 & 0,40 & 0,38 & 0,36 & 0,33 & 0,30 & 0,28 & 0,48 \\
\hline$\varepsilon_{\text {tapped }}$ & Quartzo \#200 & 0,42 & 0,42 & 0,38 & 0,36 & 0,35 & 0,32 & 0,29 & 0,36 \\
\hline \multirow[t]{2}{*}{ Índice de Hausner } & Quartzo \#600 & 1,06 & 1,10 & 1,14 & 1,20 & 1,30 & 1,37 & 1,58 & 1,95 \\
\hline & Quartzo \#200 & 1,06 & 1,07 & 1,13 & 1,18 & 1,20 & 1,29 & 1,35 & 1,87 \\
\hline Compressibilidade & Quartzo \#600 & 2,30 & 1,80 & 2,40 & 4,24 & 5,84 & 10,37 & 16,07 & 22,95 \\
\hline a $15 \mathrm{kPa}(\%)$ & Quartzo \#200 & 2,30 & 1,99 & 2,03 & 2,23 & 3,45 & 3,81 & 8,03 & 16,57 \\
\hline Ângulo de repouso & Quartzo \#600 & 38,0 & 38,5 & 40,3 & 39,5 & 45,0 & 43,8 & 47,0 & 58,5 \\
\hline$\left({ }^{\circ}\right)$ & Quartzo \#200 & 38,0 & 38,5 & 40,0 & 40,5 & 41,5 & 44,0 & 47,5 & 51,8 \\
\hline Energia Básica de Fluxo & Quartzo \#600 & 5510,3 & 4737,9 & 4106,4 & 3880,7 & 3516,5 & 2929,3 & 1733,1 & 684,7 \\
\hline $\mathrm{BFE}(\mathrm{mJ})$ & Quartzo \#200 & 5510,3 & 4220,4 & 4405,1 & 4149,0 & 4088,0 & 3790,3 & 3299,4 & 954,3 \\
\hline Índice de Fluxo & Quartzo \#600 & 1,14 & 1,08 & 1,07 & 1,10 & 1,16 & 1,34 & 2,20 & 2,03 \\
\hline FRI & Quartzo \#200 & 1,14 & 1,11 & 1,09 & 1,08 & 1,10 & 1,16 & 1,31 & 2,30 \\
\hline Energia de Aeração & Quartzo \#600 & 661,3 & 33,2 & 27,9 & 23,1 & 29,5 & 52,8 & 160,5 & 122,6 \\
\hline $\mathrm{a} 40 \mathrm{~mm} / \mathrm{s}(\mathrm{mJ})$ & Quartzo \#200 & 661,3 & 123,3 & 32,3 & 19,0 & 16,9 & 19,0 & 38,8 & 53,5 \\
\hline Relação de Aeração & Quartzo \#600 & 8,33 & 142,85 & 146,98 & 167,80 & 119,34 & 55,50 & 10,80 & 5,58 \\
\hline$\left(B F E / E_{40 \mathrm{~mm} / \mathrm{s}}\right)$ & Quartzo \#200 & 8,33 & NA & 136,28 & 218,81 & 242,44 & 199,83 & 85,10 & 17,85 \\
\hline
\end{tabular}

Os tamanhos médios volumétricos obtidos para a amostras comerciais de areia, o quartzo \#200 e o quartzo \#600 foram de $270,80 \mu \mathrm{m}, \quad 23,88 \mu \mathrm{m}$ e $9,55 \mu \mathrm{m}$, respectivamente. A análise granulométrica revelou ainda que amostras comerciais de quartzo \#200 e quartzo \#600 não são monodispersas, mas a areia sim.

A incorporação de partículas de quartzo na areia foi detectada na análise granulométrica, que passou a ter um comportamento bi-disperso para baixos teores de quartzo $(3 \%$ e $6 \%)$ e, posteriormente, apresentou um comportamento polidisperso para teores acima de 15\%. Entretanto, independentemente do tipo da curva de distribuição granulométrica obtida, o tamanho médio das misturas areia-quartzo decresceu com o aumento do teor de quartzo adicionado.

A densidade real apresentou valores consideravelmente constantes apesar da incorporação de partículas de quartzo na amostra original de areia, uma vez que ambos materiais são constituídos pela mesma substância química: dióxido de silício.

Observa-se uma tendência da densidade aparente das misturas de areia e quartzo diminuir com a adição de quartzo, ocorrendo tal diminuição a partir de teores de $10 \%$ para o quartzo $\# 600$ e a partir de $15 \%$ para o quartzo \#600. Em teores inferiores a estes mencionados, nenhuma alteração na 
densidade aparentes das duas misturas foi observada.

Figura 1 - Distribuição granulométrica para a mistura areia-quartzo \#600.

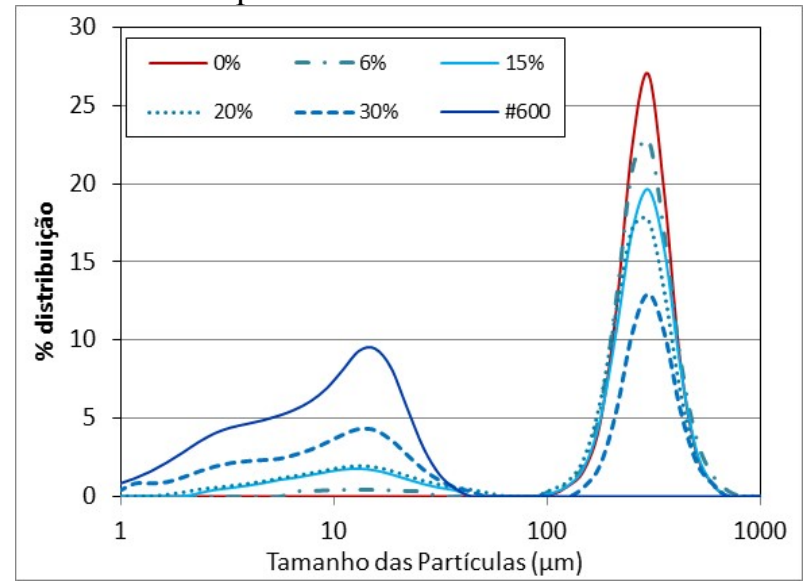

Figura 2 - Distribuição granulométrica para a mistura areia-quartzo \#200.

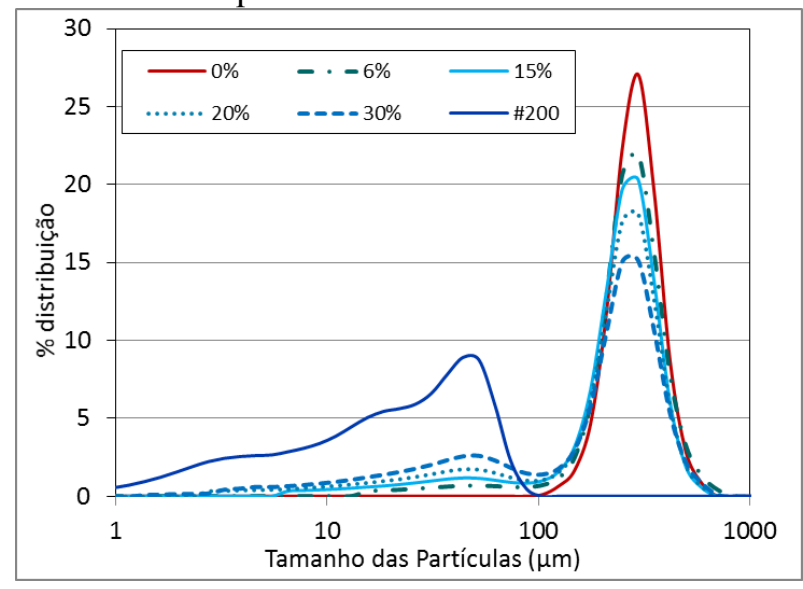

Já as densidades compactadas após 2000 batidas apresentaram um mesmo comportamento crescente para os dois tipos de misturas areia-quartzo, independente da granulometria do quartzo empregada.

A partir das análises das densidades foi possível obter o valor das porosidades das amostras, que também estão apresentados na Tabela 1. O quartzo \#600 apresentou a maior porosidade dentre as amostras comerciais, e as misturas confeccionada com este material foram os que apresentaram acréscimos da porosidade com o aumento de teor de finos.

O Índice de Hausner calculado indica que o acréscimo de partículas menores nas misturas de areia-quartzo dificulta o escoamento do material devido à intensificação da coesão, sendo que as misturas contendo partículas de quartzo \#600 as que apresentaram os maiores índices, indicando uma maior resistência ao escoamento.

O ângulo de repouso sofre influência análoga ao do Índice de Hausner, uma vez que o escoamento do material torna-se mais difícil à medida que o ângulo de repouso aumenta, evidenciado pelo fato das misturas de areia e quartzo \#600 apresentarem os maiores valores do ângulo de repouso e, consequentemente, um comportamento mais coesivo.

O teste de compressibilidade evidenciou que as misturas de areia e quartzo \#600 apresentam as maiores reduções de volume quando submetida a compressão direta de $15 \mathrm{kPa}$. Isto pode ser devido ao fato, já mencionado acima a partir dos diversos resultados experimentais, de que o quartzo \#600 é o material mais coesivo e que, devido a esta coesão, tem uma maior tendência a formar aglomerados. Estes aglomerados podem conter espaços vazios no seu interior, explicado pela maior porosidade e menor densidade aparente destas amostras, e acabam sofrendo colapso em sua estrutura quando submetido a compressão direta, acarretando na maior compressibilidade observada.

Em relação aos testes dinâmicos, os resultados dos testes de estabilidade e fluxo variável para misturas de areia e quartzo \#600 estão apresentados na Figura 3, e os das misturas de areia e quartzo \#200, na Figura 4. Os resultados dos testes de aeração para ambas misturas são apresentados na Figura 5.

$\mathrm{O}$ teste de estabilidade e de fluxo variável revelou que as misturas de areia e quartzo \#600 foram as que demandaram uma menor energia básica de fluxo quando comparadas com os mesmos teores das misturas areia e quartzo \#200. 


\section{ENEMP \\ CONGRESSO BRASILEIRO \\ DE SISTEMAS
São Carlos - SP}

Em relação as amostras comerciais, a areia pura demandou a maior energia de básica de fluxo, 5510,31mJ, seguida do quartzo \#200 com 945,31 mJ e, finalmente, o quartzo \#600 com $684,66 \mathrm{~mJ}$.

$O$ fato de se necessitar de menos energia para movimentar tanto o quartzo \#600 quanto as misturas com ele confeccionadas não significa que elas apresentam menores interações entre suas partículas, mas complementam a conclusão previamente estabelecida de que estas são as amostras mais coesivas. Partículas coesivas possuem maior

Figura 3 - Teste de estabilidade (BFE) e fluxo variável (VFR) para mistura areia-quartzo \#600.

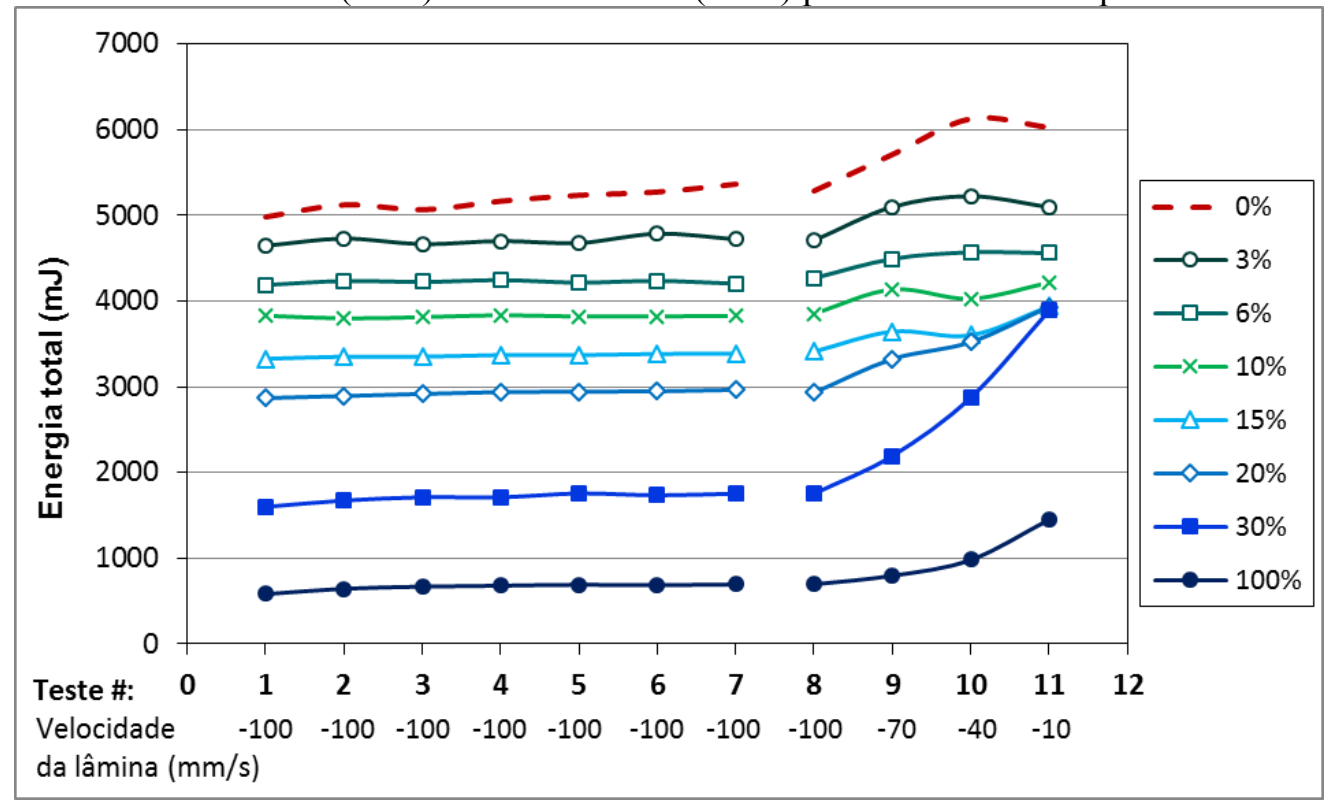

Figura 4 - Teste de estabilidade (BFE) e fluxo variável (VFR) para mistura areia-quartzo \#200. 


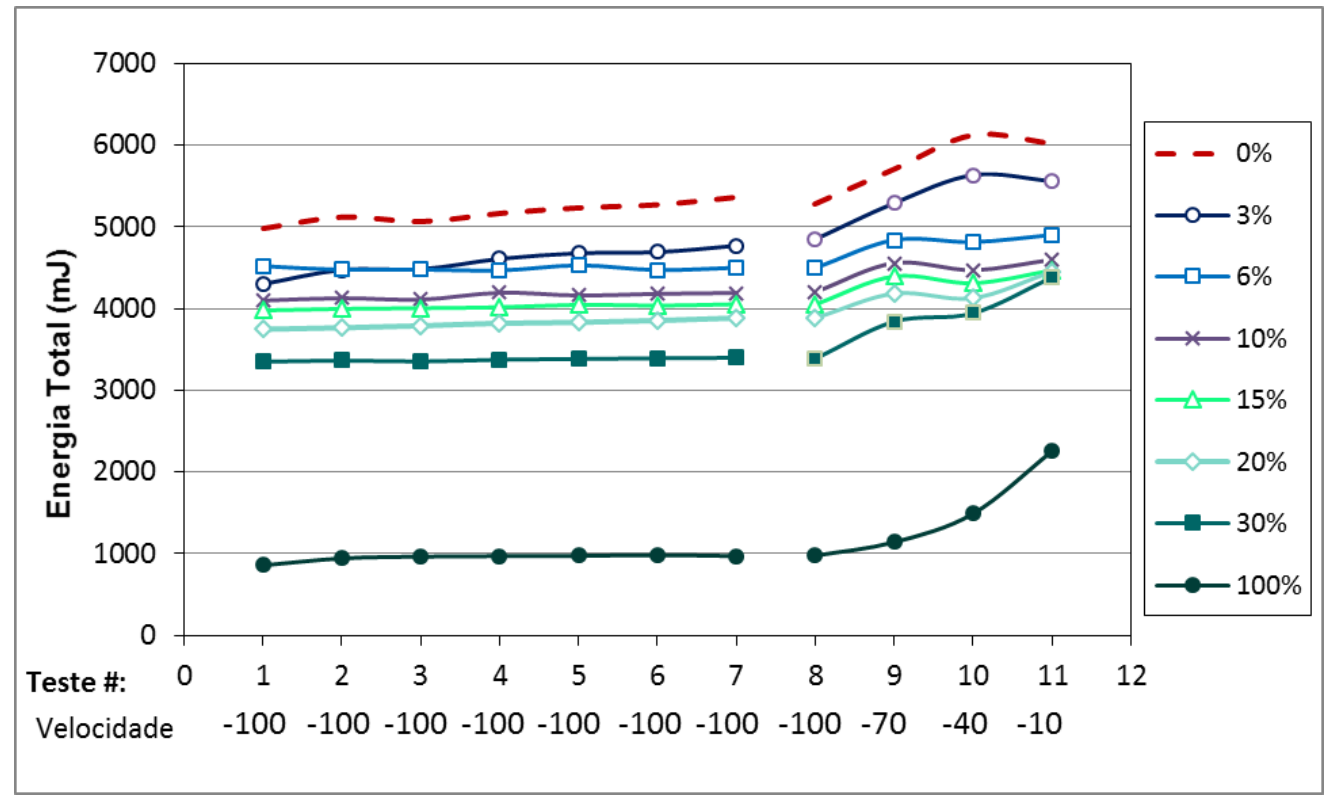

Figura 5 - Teste de aeração para as misturas de areia-quartzo \#200 e areia-quartzo \#600

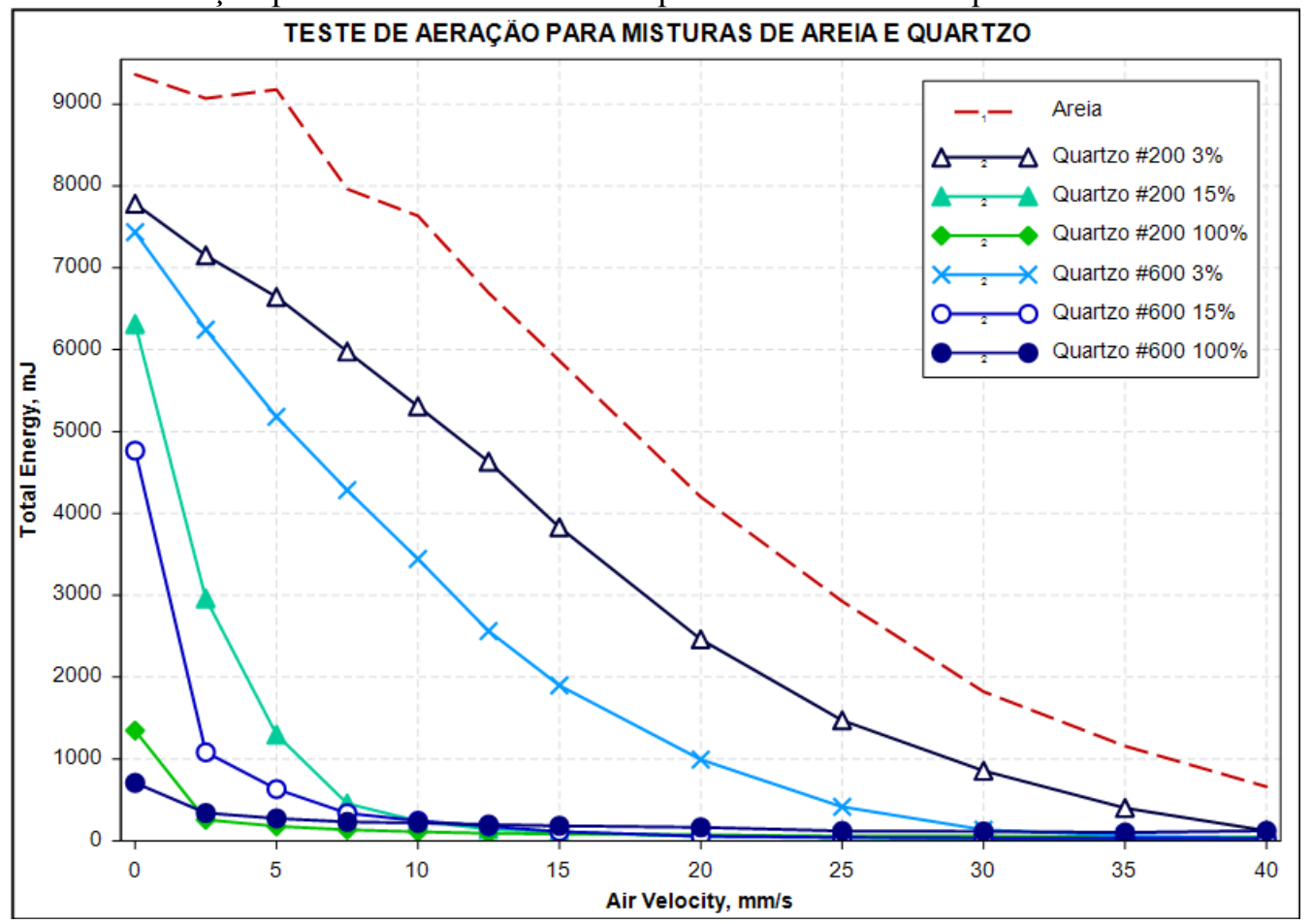

O teste de fluxo variável (VRF), que relaciona as energias de fluxo ao se variar a velocidade da lâmina durante $\mathrm{o}$ teste $\mathrm{e}$ quantifica esta relação pelo índice FRI (flow rate index), mostrou um importante aumento deste índice a partir de teores de $10 \%$ para a mistura areia-quartzo $\# 600$ e $15 \%$ para a mistura areia-quartzo \#200.
Assim, os teores de finos dos dois tipos de misturas areia-quartzo para os quais o FRI começa a apresentar alterações em seu comportamento foram os mesmos teores observados nas variações significativas da densidade e porosidade aparente destas amostras. Desta forma, conclui-se que os testes dinâmicos VRF são sensíveis as 
pequenas oscilações do comportamento reológico de pós, obtendo-se as mesmas conclusões com respeito as alterações nas propriedades físicas do meio pulverulentos avaliadas através dos tradicionais testes clássicos no estado estático.

Uma vez estabelecida a importância dos testes reológicos no comportamento do escoamento de materiais pulverulentos, observa-se através das Figuras 3 e 4 que as amostras de areia e quartzo \#600 apresentam uma inclinação mais acentuada do teste VRF, principalmente para o teor de $30 \%$ em relação as amostras de areia e quartzo 200\#. Quanto mais acentuada for esta curva, maior será o valor do FRI, indicando um escoamento mais problemático do material particulado analisado.

Os resultados do teste de aeração mostram uma sensível diminuição dos valores da energia dispendida pela lâmina para permear o leito de pó quando este está aerado. Neste teste esta energia não é mais referenciada como energia básica de fluxo (BFE) mas como energia de aeração (AE).

O comportamento da areia e das amostras de quartzo no teste de aeração foram bastante discrepantes. Um mínimo da energia dispendida é obtido para velocidades do ar de aeração próximo de $40 \mathrm{~mm} / \mathrm{s}$, enquanto que para as amostras de quartzo este mínimo é obtido em velocidades de inferior a $5 \mathrm{~mm} / \mathrm{s}$.

Outra conclusão importante é que uma mesma redução da energia de aeração (AE) ou, em outras palavras, um melhor escoamento, é obtido em condições de aeração inferior para as misturas de areia e quartzo \#600.

Uma vez que as misturas areia-quartzo \#600 apresentam maiores porosidades e, consequentemente, menor interação partículapartícula, a quantidade de ar necessária para minimizar estes contatos remanescentes e reduzir a energia dispendida pela lâmina para deslocar as partículas em sua trajetória através do leito de pó é menor. Já as misturas areia- quartzo \#200 necessitam de quantidade de ar maior para, primeiro chegar na mesma condição de porosidade das amostras areiaquartzo \#600 e, posteriormente, ter o efeito de redução da energia de movimentação da lâmina.

Finalmente, o teste de aeração permitiu identificar as condições de aeração, através dos valores de velocidade do ar injetado às amostras, para as quais ocorrem a minimização da energia de aeração e, possivelmente, a fluidização do leito de material a partir desta velocidade.

Outro parâmetro obtido a partir do teste de aeração é a relação de aeração (RA), que é a razão entre a energia básica de fluxo (BFE) dispendida pela lâmina sem a aeração do leito pela energia dispendida sob uma certa condição de aeração. Neste trabalho a condição de aeração utilizada foi a máxima observada para a areia pura, ou seja, com velocidade do ar de $40 \mathrm{~mm} / \mathrm{s}\left(\mathrm{AE}_{40 \mathrm{~mm} / \mathrm{s}}\right)$.

Assim, como regra geral, quanto maior a razão de aeração (RA) menos coesivo é o material, caracterizando assim a mistura de areia e quartzo\#600 15\% como o material mais coesivo dentro os apresentados na Figura 5

Comparando-se todos os dados da razão de aeração apresentados na Tabela 1, é possível observar uma mudança abrupta deste valor a partir do teor de $10 \%$ para a mistura quartzo-areia \#600, e a partir de 15\%-20\% para a mistura areia-quartzo \#200. Estes são os mesmos teores em que as demais propriedades também sofreram alterações, enfatizando mais uma vez a sensibilidade do teste dinâmico na determinação das variações das propriedades de fluxo (escoamento) de materiais particulados.

\section{CONCLUSÕES}

A dimensão das partículas pode ser uma característica natural do material ou uma característica resultante de um processo 
prévio de fragmentação e, assim como outras variáveis, sua magnitude influencia na aptidão ao escoamento de materiais particulados.

Este trabalho evidencia a necessidade do estudo das origens, estruturas de empacotamento e a composições do meio granular constituído partículas monodispersas ou polidispersas, além de sua caracterização de sob condições estáticas e dinâmicas para compreensão do comportamento desses materiais.

Inicialmente, a coesão das misturas areia-quartzo forma correlacionada com o ângulo de repouso e o Índice de Hausner que demonstraram que a fluidez era prejudicada com o teor de finos presente na mistura.

As densidades e porosidades das misturas apresentaram mudança de comportamento significativa em certos teores específicos de finos, os quais também obtidos através de testes dinâmicos de estabilidade (BFE), fluxo variável (VFR) e aeração (AE).

Durante os testes dinâmicos, a coesão, a desaeração, a aglomeração, a segregação e a carga eletrostática podem interferir na estabilidade do leito e, consequentemente, na energia básica (BFE) determinada. Porém, o conhecimento das propriedades físicas do material é essencial para análise dos resultados dinâmico, uma vez que a forma e textura do material, o efeito da coesão e segregação do bulk, entre outros fatores, caracterizam o fluxo e delineiam o trajeto pelo qual o ar permeia as partículas durante o movimento da lâmina ao transitar através da amostra.

Finalmente, a ciência da tecnologia dos pós é composta por inúmeras análises e por um vasto intervalo de padrões, possibilitando a obtenção de diferentes valores para uma mesma propriedade. Cabe ao usuário adotar as diretrizes que melhor representam as condições reais que o material particulado será submetido no processo industrial assegurar melhor controle de qualidade, menor tempo de inatividade e um o mínimo de emissões ambientais.

\section{REFERENCIAS}

CAMPOS, M. M., Análise da Escoabilidade de Pós. Dissertação de Mestrado em Engenharia Química, UFSCar, 2012.

FREEMAN, R., COOKE, J. Understanding powder behavior by measuring bulk, flow and shear properties. Pharmaceutical Technology Europe. v. 18, n. 9, 2006.

FREEMAN TECHNOLOGY, FT-4 Powder Rheometer User's Manual, 2008.

RHODES, M. Introduction to particle technology. $2^{\mathrm{a}}$ ed.; John Wiley \& Sons Ltd. 2008.

SANTOS, C. M., CONDOTTA, R. Avaliação do efeito da distribuição granulométrica nas propriedades de escoamento de materiais granulares. In: Congresso Brasileiro de Engenharia Química, 20, Anais XX COBEQ 2014, Florianópolis, 2014.

U.S. Pharmacopeia. Disponível em: $<$ www.pharmacopeia.cn/v29240/usp29nf24s0 c1174.html> Acesso em: Junho de 2015. 